\title{
PARTICIPAÇÃO SOCIAL, PLANEJAMENTO URBANO E PROMOÇÃO DA SAÚDE EM CAMPO GRANDE (MS)
}

\author{
SOCIAL PARTICIPATION, URBAN PLANNING, AND THE PROMOTION OF HEALTH IN \\ CAMPO GRANDE (STATE OF MATO GROSSO DO SUL)
}

\author{
PARTICIPACIÓN SOCIAL, PLANIFICACIÓN URBANA Y PROMOCIÓN DE LA SALUD EN \\ CAMPO GRANDE (ESTADO DEL MATO GROSSO DO SUL)
}

\author{
Crhistinne Cavalheiro Maymone Gonçalves ${ }^{1}$ \\ Cláudia Maria Bógus ${ }^{2}$
}

\begin{abstract}
Resumo A pesquisa apresentada neste artigo buscou conhecer a participação social em uma iniciativa da promoção da saúde desenvolvida em Campo Grande, Mato Grosso do Sul. Tratou-se de pesquisa desenvolvida em 2009 com abordagem qualitativa, em que foram realizados análise documental, entrevistas (com gestores e técnicos), grupos focais (com conselheiros regionais) e análise de conteúdo com triangulação dos dados. A percepção quanto à participação social não se restringiu à experiência, pois destacaram-se a institucionalização de canais de participação no município e os conselhos regionais urbanos, considerados como avanço nos processos democráticos, propulsores de maior envolvimento dos conselheiros nas decisões do planejamento urbano. Porém, barreiras ao exercício democrático foram ressaltadas: necessidade de formação política de conselheiros, fragilidade de presença da população nas instâncias participativas, dificuldade de articulação com o legislativo, falta de conhecimento e acesso à informação, dificuldades na atuação como conselheiro e descrença no processo participativo, causando evasão de lideranças. Observaram-se o fortalecimento desses espaços colegiados e a união das lideranças nos bairros em torno de objetivos comuns, com a formação de uma espiral crescente de participação, estimulada por uma rede de apoio comunitário. Palavras-chave participação social; políticas públicas; promoção da saúde.
\end{abstract}

Abstract The study presented in this article aimed to analyze social participation in a health promotion initiative carried out in the city of Campo Grande, Mato Grosso do Sul, Brasil. This survey was conducted in 2009 based on a qualitative approach involving document analysis, interviews (with managers and technicians), focus groups (regional directors), and content analysis with data triangulation. The views on social participation were not restricted to the experience, since the institutionalization of participation channels in the city and regional urban boards stood out, and they are seen as progress made in the democratic processes and as drivers of the greater involvement of the members of the board in urban planning decisions. However, barriers to democratic exercise were highlighted: The need for training in policy for advisers, the fragility of the population's presence in participatory instances, difficulty in coordinating with the legislative, a lack of knowledge and access to information, difficulties in acting as an adviser, and disbelief in the participatory process, which causes the evasion of leaderships. It was noticed that these collegiate spaces were strengthened and that the leaders in the neighborhoods came around common objectives, forming a growing spiral of participation driven by a network of community support.

Keywords social participation; public policy; health promotion. 


\section{Introdução}

Desde a década de 1980, concomitantemente ao processo de redemocratização brasileira e à conformação de um novo contexto político-institucional que criou espaços institucionais para a participação e a representação política da sociedade civil, um significativo movimento pela melhoria das condições de vida, trabalho e saúde fortaleceu-se no Brasil. Esse movimento, implementado por iniciativas no campo da promoção da saúde, consolidou-se alicerçado na participação social, na perspectiva de estimular indivíduos e comunidades em prol da unificação de esforços para articulação e implantação de políticas públicas desencadeadoras de transformações nos espaços locais.

No Brasil, o poder concentrou-se hegemonicamente nas mãos do Estado, em relações sociais de dominação. Sales (1994) aborda o cerne da cultura política da dádiva e o conceito de cidadania concedida, legado do modelo escravista, em que os direitos básicos à vida, à liberdade individual, à justiça, à propriedade, ao trabalho, enfim, todos os direitos civis chegavam ao homem livre como uma dádiva do senhor de terras. Essa experiência histórica deixou resquícios na conformação da cultura político-institucional atual (Guizardi e Pinheiro, 2006).

No final da década de 1980, com o processo de redemocratização do país, após o período de ditadura militar, começaram a surgir espaços de participação institucionalizada, por meio da criação de conselhos de vários tipos. Tatagiba (2002, p. 49) descreve três tipos de conselhos:

Conselhos de programas:

(...) vinculados a programas governamentais concretos, em geral associados a ações emergenciais bem delimitadas quanto ao seu escopo e clientela (...). Dizem respeito a metas incrementais, em geral vinculadas ao provimento concreto de acesso a bens e serviços elementares ou a metas de natureza econômica (...). Exemplos são os Conselhos Municipais de Desenvolvimento Rural, de Alimentação Escolar, de Habitação, de Emprego, de Distribuição de Alimentos.

Conselhos de políticas:

(...) ligados às políticas públicas mais estruturadas ou concretizadas em sistemas nacionais (...). Neste situam-se os Conselhos (...) de Saúde, de Assistência Social, de Educação, de Direitos da Criança e do Adolescente (...). Dizem respeito à dimensão da cidadania, à universalização de direitos sociais e à garantia do exercício desses direitos. Zelam pela vigência desses direitos, garantindo sua inscrição ou inspiração na formulação de políticas e respeito na execução delas.

Conselhos temáticos:

(...) sem vinculação imediata a um sistema ou legislação nacional, existem na 
esfera municipal por iniciativa local ou por estímulo estadual. Em geral, associam-se a grandes movimentos de ideias ou temas gerais que, naquele município, por força de alguma peculiaridade de perfil político ou social, acolhem ou enfatizam o tema em sua agenda (...). Neste, incluem-se os Conselhos Municipais de Direitos da Mulher, de Cultura, de Esportes, de Transportes, de Patrimônio Cultural, de Urbanismo etc.

Ainda no final dos anos 1980, as denominações de participação cidadã e participação social se destacaram. O conceito de participação cidadã remete à

universalização dos direitos sociais, ampliação do conceito de cidadania, e em nova compreensão sobre o papel e o caráter do Estado, remetendo à definição das prioridades nas políticas públicas a partir de um debate público (Gohn, 2003, p. 57).

Ou seja: a participação passa a ser "concebida como intervenção social periódica e planejada, ao longo de todo o circuito de formulação e implementação de uma política pública" (Gohn, 2003, p. 57). Já a participação social remete à construção de um "modelo geral/ideal na relação sociedade/Estado" (Gohn, 2003, p. 57), em que "o conceito de mobilização encontra-se ressignificado no sentido de direcionamento para alcance de objetivos comuns" (Gohn, 2003, p. 57).

O conceito de participação cidadã remete à redefinição de laços entre o espaço institucional e as práticas da sociedade civil organizada em que: “O Estado reconhece a existência dos conflitos na sociedade e as divergências nas formas de equacionamento e resolução das questões sociais, entre diferentes grupos, e participa da arena de negociação entre eles" (Gohn, 2004, p. 29). Isso é possível se mudanças culturais e cívicas ocorrerem, tendo como marcos referenciais os princípios democráticos de justiça, liberdade, solidariedade e igualdade com respeito às diferenças, pois mudanças democráticas só podem ser decorrentes de mudanças no Estado e na sociedade civil.

Nos espaços institucionalizados do país ainda se observam fragilidades nessa prática de participação cidadã, tais como falta de prestação de contas dos representantes aos seus representados e falta de cobrança dos representados em relação às ações dos representantes, o que resulta em descrença nos processos participativos (Bógus e Westphal, 2007).

Em relação à descrença, Labra (2005) aponta o descrédito dos conselheiros usuários quanto ao controle social, vinculado às questões de desrespeito às deliberações dos conselheiros, às regras de paridade, à complexidade técnica das discussões e às desigualdades do país. A falta de confiança no poder público relaciona-se à percepção quanto à baixa capacidade de atendimento das demandas e à pouca permeabilidade no exercício do controle social. 
Diferentes formatos estabeleceram-se com a inserção de novos atores no processo decisório local, experiências restritas de participação - resumidas à voz dos cidadãos -, até experiências que promovem mudanças significativas nas relações de poder entre os atores locais. Diante desses formatos é que se questiona a suficiência da representação do interesse coletivo e do papel como 'decisores' de fato (Souza, 2004).

A forma não equitativa de participação é encontrada em experiências diversas, em que há limitada participação de atores não governamentais nos processos de tomada de decisões. Assim, a legitimidade do processo institucional participativo na construção do interesse coletivo é questionada por Milani (2008, p. 555), ao afirmar que essa forma de participação "pode aumentar a qualidade de transparência dos dispositivos institucionais", mas nem sempre assegura o processo participativo.

Diante dos limites e potencialidades desses espaços deliberativos, outro tema mereceu ser abordado: a formação de conselheiros. Bógus (2009, p. 177) analisou seis conselhos gestores de políticas públicas da cidade de São Paulo e teve como um dos resultados "que faltam aos conselheiros conhecimentos, recursos argumentativos e força política para se posicionarem nas decisões dos Conselhos". Ao se considerar que os espaços e instâncias participativas estão consolidados institucionalmente e precisam ser mais qualificados, há necessidade da formação das pessoas que ocupam ou ocuparão esses espaços, e os processos de capacitação de conselheiros devem contemplar, nas suas propostas de cursos, “conteúdos voltados para uma formação política geral, sem deter-se, exclusivamente, em aspectos específicos ligados à área de atuação do conselho" (Bógus, 2009, p. 178).

A autora destaca que tradicionalmente capacitações são feitas apenas para conselheiros, o que configura a possibilidade de se "criar um grupo elitizado que tenderia a perpetuar-se nas instâncias participativas", o que poderia "reproduzir mecanismos de exclusão social presentes na sociedade brasileira" (Bógus, 2009, p. 178). Para ampliação e maior capilaridade das mais diversas experiências associativas no meio urbano, ela propõe o desenvolvimento de iniciativas de formação dirigidas também a instituições e associações que estão fora do sistema político tradicional, de forma participativa, em todas as etapas: nos objetivos, no desenvolvimento e na execução das atividades.

De forma geral, muitos estudos já vêm observando os avanços da participação social nas políticas públicas no país, tanto na "dimensão de constituição de identidades coletivas, organizativa e mobilizatória", quanto no delinear de formas alternativas de intervenção voltadas para a dinâmica social, possibilitando a construção democrática do planejamento e da gestão urbana (Brasil et al., 2013, p. 15).

Ao se considerar tal cenário da participação social em saúde no Brasil nas últimas décadas, delineou-se o estudo aqui apresentado para se conhecerem 
as percepções de representantes de governo (gestores e técnicos) e da população (conselheiros) quanto à participação no planejamento e implementação de uma iniciativa no campo da promoção da saúde (Projeto Viva Seu Bairro PVSB) no município de Campo Grande, capital do estado do Mato Grosso do Sul, no período de 2001 a 2004. O PVSB objetivou possibilitar o desenvolvimento sustentável e participativo em seis áreas, atingindo 137.783 pessoas, ou seja, 20,95\% da população total do município (Campo Grande, 2001).

\section{O processo de planejamento no município}

Campo Grande, em 1985, possuía adensamento populacional expressivo, desorganização da estrutura urbana e insucesso de tentativas anteriores de planos de intervenção para o ordenamento urbano.

Em 1987, a lei n. 2.383 criou a Estrutura Básica da Secretaria Municipal do Planejamento, a Unidade de Planejamento Urbano de Campo Grande, encarregada de formular a política urbana. A participação da comunidade nas discussões sobre política urbana formalizou-se com a criação do Conselho Municipal de Desenvolvimento Urbano (CMDU), pelo decreto n. 5.484, de 9 de março de 1987. Mas apenas em 1995 Campo Grande teve seu primeiro Plano Diretor, por meio da lei complementar n. 5, de 22 de novembro de 1995, que criou os conselhos regionais urbanos (CRUs) (Campo Grande, 2005). O município foi dividido em nove regiões, sete na sede urbana e duas nos distritos (Rochedinho e Anhandui) (Figura 1).

Figura 1

Concentrações populacionais por região urbana - população residente no ano 2000 em Campo Grande (MS)

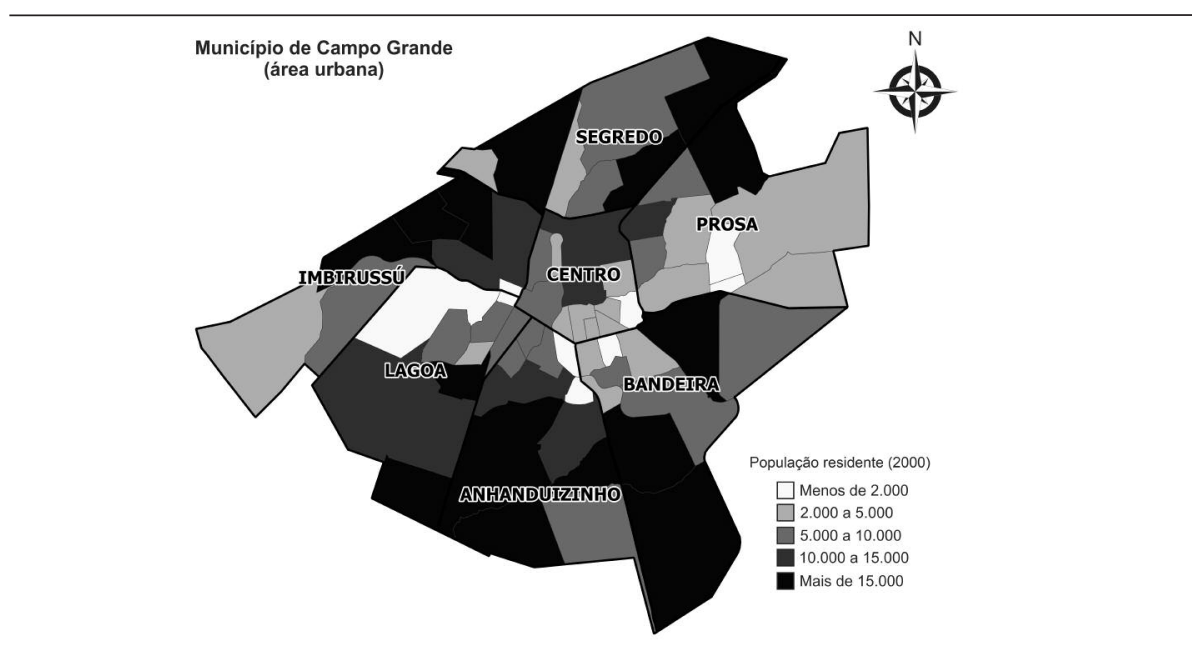

Fonte: Campo Grande, 2005, p. 53 
Os CRUs foram criados com o objetivo de acompanhar o desenvolvimento do Plano Diretor, discutir a proposta orçamentária anual e acompanhar a elaboração dos planos locais nas regiões urbanas. Regulamentados pelo decreto n. 7.361, de 13 de dezembro de 1996, são consultivos constituídos de representantes de entidades com sede e atuação no âmbito municipal, em suas regiões urbanas (Campo Grande, 2007). Compõem-se de: entidades locais - entidades comunitárias, de educação e da saúde, em atividade no bairro; e entidades regionais - entidades voltadas ao setor econômico, ambiental, cultural, de assistência social e afins, com atividade na região. Têm eleições a cada dois anos, e o preenchimento das vagas se dá por votação. Concorrem entre si as entidades cadastradas pertencentes ao mesmo bairro, ficando assegurado, no mínimo, um assento para as entidades de saúde, um assento para as entidades de educação e um assento para as entidades comunitárias (Campo Grande, 2006a, 2006b).

A instalação dos CRUs deu-se a partir de julho de 1997, sendo a primeira eleição em 1998, com 166 conselheiros. Em 2002, foram 514 conselheiros regionais; e em 2004, 449 conselheiros. O processo eleitoral para o mandato 2006-2008 resultou na nomeação de 363 conselheiros.

\section{Procedimentos para a coleta da pesquisa}

A pesquisa ${ }^{3}$ realizada com gestores incluiu prefeitos do período de 1997 a 2008 e o secretário municipal de saúde de 1997 a 2004; com técnicos, incluiu membros da unidade técnica central (UTC), gestora da iniciativa. Os conselheiros regionais urbanos foram os de 1998 a 2006, períodos anterior, posterior e durante a iniciativa. Para identificar os representantes de governo e os da população, realizou-se a análise documental em diários oficiais do município e relatórios técnicos do PSVB (Figura 2).

Figura 2

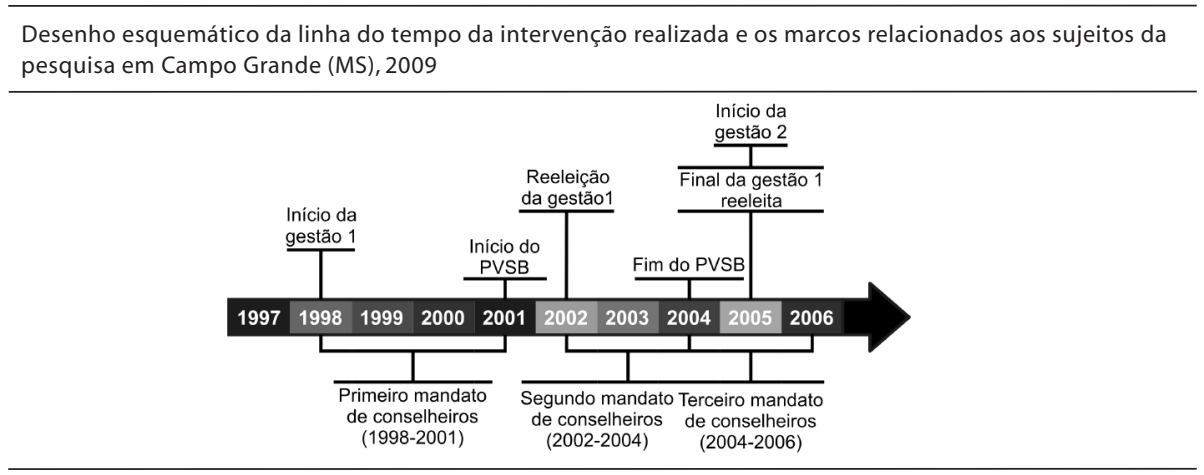

Fonte: As autoras. 
Identificaram-se os conselheiros titulares no período de 1998 a 2006 classificando-os por entidade de representação, período e região urbana, observando-se os percentuais de cada região quanto à participação na totalidade dos períodos analisados. Com a representatividade numérica dos conselheiros, procedeu-se às planilhas nominais por entidade: locais (saúde, educação e movimento comunitário) e regionais, excluindo-se as repetições ocorridas no mesmo segmento em períodos diversos, mas preservadas as repetições que ocorreram em segmentos diferentes. Foram calculados os percentuais de representatividade para o número de trinta e preservados na escolha dos selecionados (Tabela 1).

\begin{tabular}{|c|c|c|c|c|}
\hline \multicolumn{5}{|c|}{$\begin{array}{l}\text { Percentual de conselheiros titulares por segmento e representação e número absoluto } \\
\text { para a escolha de participação nos grupos focais - Campo Grande (MS), } 2009\end{array}$} \\
\hline & \multirow{2}{*}{ Segmento } & \multicolumn{2}{|c|}{ Conselheiros } & \multirow{2}{*}{$\begin{array}{l}\text { Número absoluto para a } \\
\text { escolha }(\mathrm{N}=30)\end{array}$} \\
\hline & & $\mathrm{n}$ & $\%$ & \\
\hline \multirow{5}{*}{ PROSA } & Saúde & 5 & 9,43 & 3 \\
\hline & Educação & 7 & 13,21 & 4 \\
\hline & Comunitário & 24 & 45,28 & 14 \\
\hline & Regional & 17 & 32,08 & 9 \\
\hline & Total & 53 & 100,0 & 30 \\
\hline \multirow{5}{*}{ ANHANDUIZINHO } & Saúde & 7 & 5,65 & 2 \\
\hline & Educação & 20 & 16,13 & 5 \\
\hline & Comunitário & 79 & 63,71 & 19 \\
\hline & Regional & 18 & 14,51 & 4 \\
\hline & Total & 124 & 100,0 & 30 \\
\hline \multirow{5}{*}{ SEGREDO } & Saúde & 3 & 6,82 & 2 \\
\hline & Educação & 4 & 9,09 & 3 \\
\hline & Comunitário & 23 & 52,27 & 16 \\
\hline & Regional & 14 & 31,82 & 9 \\
\hline & Total & 44 & 100,0 & 30 \\
\hline \multirow{5}{*}{ LAGOA } & Saúde & 4 & 7,02 & 2 \\
\hline & Educação & 10 & 17,54 & 5 \\
\hline & Comunitário & 27 & 47,37 & 14 \\
\hline & Regional & 16 & 28,07 & 9 \\
\hline & Total & 57 & 100,0 & 30 \\
\hline \multirow{5}{*}{ IMBIRUSSU } & Saúde & 2 & 4,35 & 1 \\
\hline & Educação & 6 & 13,04 & 4 \\
\hline & Comunitário & 26 & 56,52 & 17 \\
\hline & Regional & 12 & 26,09 & 8 \\
\hline & Total & 46 & 100,0 & 30 \\
\hline \multirow{5}{*}{ BANDEIRA } & Saúde & 6 & 8,69 & 3 \\
\hline & Educação & 5 & 7,25 & 2 \\
\hline & Comunitário & 41 & 59,42 & 18 \\
\hline & Regional & 17 & 24,64 & 7 \\
\hline & Total & 69 & 100,0 & 30 \\
\hline
\end{tabular}

Fonte: As autoras. 
Para a localização dos conselheiros utilizaram-se o cadastro telefônico do Instituto Municipal de Planejamento Urbano e Meio Ambiente (Planurb) e a participação nas reuniões mensais de cada CRU, de modo a tentar identificar os contatos dos conselheiros selecionados. Outros critérios foram obedecidos: residir em Campo Grande, lembrar-se do PVSB e ter disposição para participar.

A opção pela realização de seis grupos focais esteve relacionada às regiões urbanas em que o projeto ocorreu, sendo um por região, com um moderador e um observador/relator e gravação. Depoimentos foram transcritos integralmente e seguiu-se a codificação, respeitados os procedimentos éticos. Utilizou-se roteiro semiestruturado com perguntas abertas sobre os temas: conhecimento da iniciativa; relação da iniciativa com as condições de vida e saúde; inserção da temática da iniciativa em pauta das reuniões do CRU, elementos da participação dos conselheiros no PVSB em todas as etapas.

Foram nove entrevistas, sendo seis com técnicos que trabalharam na UTC: um coordenador do Planejamento, um representante da Secretaria Municipal de Saúde Pública, três representantes da Secretaria Municipal de Serviços e Obras Públicas e um representante da Secretaria Municipal de Assistência Social. As demais foram realizadas com os gestores, com roteiro específico visando permitir o surgimento de categorias empíricas e dos significados relativos à pesquisa, ao contexto da iniciativa e à participação social. Todas foram gravadas e transcritas para a análise dos dados (Quadro 1).

Quadro 1

\begin{tabular}{|cc|}
\hline $\begin{array}{c}\text { Tipologia utilizada e letra correspondente à fala de acordo } \\
\text { com o instrumento utilizado - Campo Grande (MS), 2009 }\end{array}$ \\
\hline Entrevistas & Siglas \\
Gestores & $\mathrm{G}$ \\
Técnicos & $\mathrm{T}$ \\
\hline Grupos focais & Siglas \\
CRU Prosa & $\mathrm{P}$ \\
CRU Segredo & $\mathrm{S}$ \\
CRU Imbirussu & $\mathrm{I}$ \\
CRU Anhanduizinho & $\mathrm{A}$ \\
CRU Bandeira & $\mathrm{B}$ \\
CRU Lagoa & $\mathrm{L}$ \\
\hline
\end{tabular}

Fonte: As autoras. 
A coleta de dados foi de março a julho de 2009. Após exaustiva leitura e organização dos dados, procedeu-se à identificação dos núcleos de sentido constantes no conjunto de depoimentos. Optou-se pela análise temática, que possibilitou a identificação da categoria participação social no PVSB e ideias-chave (importância da participação, estímulo do poder público à participação, fragilidades quanto à participação e formas de participação) (Figura 3).

\section{Figura 3}

Categoria emanada nos depoimentos, de acordo com as dimensões do PVSB e respectivas ideias-chave Campo Grande (MS), 2009

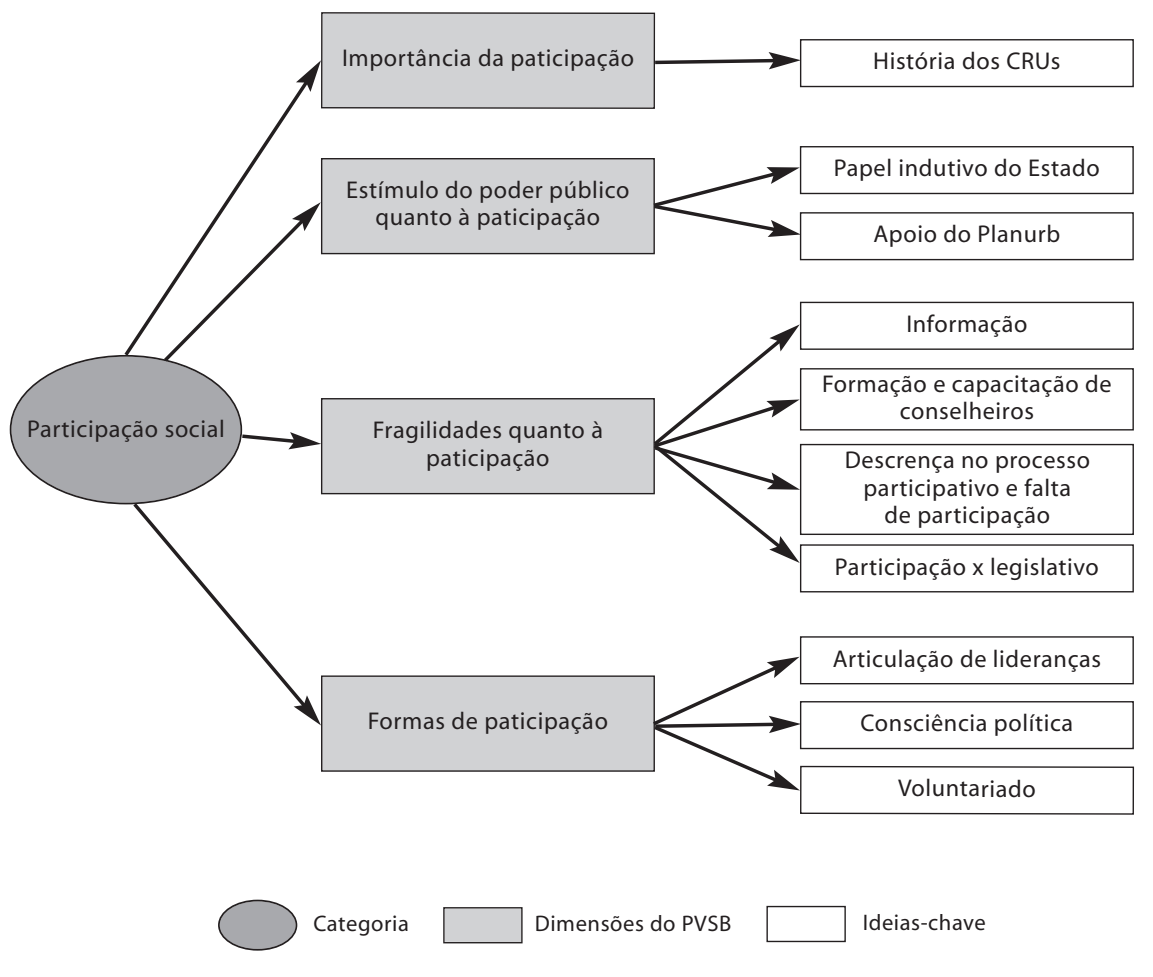

Fonte: As autoras.

Utilizou-se a triangulação de dados, pela possibilidade de se observar a realidade de distintos ângulos, fazendo dialogar questões objetivas e subjetivas, respeitando-se "a análise do contexto, da história, das relações, das representações e da participação", o que permitiu a ampliação do "espectro de contribuições teórico-metodológicas, de forma a perceber movimentos, estruturas, ação dos sujeitos, indicadores e relações entre micro e macrorrealidades" (Minayo, 2005, p. 29). 
O estudo foi aprovado pelo Comitê de Ética em Pesquisa da Faculdade de Saúde Pública da Universidade de São Paulo (FSP/USP), conforme o número de protocolo 1.674/2007.

\section{Percepções sobre a participação social}

A categoria da participação social emanada dos depoimentos está relacionada às dimensões relativas à importância da participação, ao estímulo do poder público quanto à participação, às fragilidades percebidas e à forma como a participação se deu. As percepções dos representantes quanto à participação social não se limitaram ao PVSB, abordando significativamente a origem institucionalizada dos canais de participação no contexto do município. Em diversos depoimentos, a origem histórica dos CRUs foi narrada por representantes do governo e da população como possibilidades concretas de espaços de participação:

Campo Grande já tinha desde 1994 os conselhos regionais (...). Eles não têm participação do poder público, só pessoas da população participam (...). Então são muito fortes porque a prefeitura discute o orçamento com os conselhos e depois vai para o desenvolvimento urbano para fechar as prioridades, um orçamento participativo de verdade (G).

(...) os resultados positivos para a cidade e para a população, o prefeito junto com as administrações considerou que isso era bom e continuou incentivando (...) porque criou toda essa expectativa, motivação das pessoas participarem (L).

Tanto gestores e técnicos quanto conselheiros descreveram o processo de participação construído ao longo dos anos, destacando o cumprimento da constitucionalidade promulgada em 1988:

A participação dos conselhos regionais foi a partir de 1996 e começo de 1997, na mudança do governo municipal (1998). Aí começou a criação dos conselhos, a colocar em prática aquilo que a Constituição já determinava (A).

Em 1987, discutimos o desenvolvimento urbano de Campo Grande; em 1988, aliás, em 1989 foi criada a lei da sessão itinerante na Câmara Municipal (...), então começou a sessão itinerante e em seguida os CRUs e a Comunidade Viva junto com o PVSB e esses conselhos que estão aí desenvolvendo os trabalhos (B).

Vale ressaltar que, na análise documental, o relatório do Planurb elenca atividades realizadas no período de 2005 a 2008. Entre outras, destacam-se 
as que têm relação com o estudo aqui apresentado: Programa Comunidade Viva, criado em 2005 com a finalidade de estabelecer condições favoráveis à participação da comunidade local na gestão democrática do município, e em atividade até a finalização deste estudo; 24 conferências locais nas regiões urbanas; realização de capacitação para 245 conselheiros regionais urbanos nos anos de 2007 a 2008, em parceria com a União da Associação Educacional Sul Mato-Grossense (Unaes); e acompanhamento de 87 reuniões ordinárias e extraordinárias e quatro mesas diretoras em 2008 (Campo Grande, 2008).

O registro histórico dos representantes apontou a apropriação da participação nessa arena política institucionalizada. Para alguns conselheiros, a participação nessa instância institucionalizada tinha o significado de 'vez e voz':

Quero parabenizar todo esse mecanismo da prefeitura para ouvir a comunidade, porque é através disso que nós temos o meio de chegar com as nossas solicitações, evidentemente que não são atendidas todas, mas nós temos que batalhar. Hoje os conselheiros têm voz, eu vejo assim, o conselheiro é muito respeitado (...) tem a vez e a voz (B).

A questão do apoio do governo como estimulador da participação foi ressaltada, na dimensão de órgão auxiliar na organização dos processos participativos, em especial pelos representantes da população:

Aprendemos a nos organizar para chegar aonde estamos, porque Campo Grande em termo de conselho é o que mais está funcionando, e o aprendizado tornou-se tão afinado, que o colegiado do Planurb, que nos orientava sempre e até hoje ele coordena nossos conselhos regionais, nos deram um horizonte além do que podíamos ver (...) hoje todo mundo vê o nosso bairro, a nossa casa, a nossa saúde, então a coisa ficou mais extensa (L).

Perceberam-se nos depoimentos admiração e respeito pelos técnicos do Planurb, enfatizando como positivo o fortalecimento das instâncias colegiadas. Notou-se, assim, a cultura da dádiva ainda arraigada no contexto político atual.

Entre as fragilidades estava a questão da importância da superação dos desafios quanto à produção, organização e acesso pleno da informação, o que comprometia o processo de participação. Um conselheiro apontou essa fragilidade presente nas instâncias de participação entre os próprios conselheiros:

A gente nunca discute, você discute o desconhecido? Então para saber, discutir, ter posição, ter ideia, você precisa conhecer. Então temos que investir em educação, que é o principio básico para transformar uma cidadania (...). O que é que nós temos que fazer na prática? (...) é trabalhar nas informações, fazer com que esse camarada fique atualizado $(\mathrm{P})$. 
Para construir relações mais simétricas de poder entre Estado e sociedade civil, há de se investir em processos de formação e mecanismos que viabilizem o acesso à informação dentro e fora das instâncias institucionalizadas de participação. Para elaboração comum de políticas públicas, ambas as partes devem ter igualdade nos processos de informação. Quando isso não ocorre, as relações de poder ficam assimétricas e comprometem o exercício da democracia. As administrações municipais carecem de reformas administrativas que permitam a consolidação da democracia, uma vez que sofrem do legado da burocracia weberiana. Uma gestão que prioriza os processos participativos deve refletir sobre isso, pois a rotatividade nos conselhos é frequente.

Em estudo sobre conselhos municipais e locais da cidade de São Paulo, Bógus (2009, p. 177) ressaltou a falta de conhecimentos, recursos argumentativos e força política para o posicionamento dos conselheiros nas reuniões, resultando na necessidade de capacitação técnica e política e "formação das pessoas que ocupam ou que virão a ocupar esses espaços, desde o não acesso a informações até o não reconhecimento do outro como interlocutor".

O processo de formação e capacitação de conselheiros é fundamental para uma participação qualificada, pois esta nem sempre é uma realidade nas instâncias. A seguir, o relato de um conselheiro sobre o tema:

O que vou fazer no planejamento do meu grupo é trabalhar nas informações, (...) quando for discutir com o secretário, não discutir brigando, porque a maioria das pessoas que vai discutir é discutir no sentido de alterar voz, ofender a pessoa. Não, você tem que discutir baseado na lei, nos argumentos (P).

A realidade vivenciada expressa a necessidade de formação e qualificação como processos essenciais para a participação representativa, que devem contemplar conteúdos amplos de formação política geral, para que os conselheiros tenham formação além dos assuntos exclusivos à área de atuação do conselho (Bógus, 2009). Esse despreparo quanto à formação política foi abordado como comprometedor do debate democrático qualificado:

Você sabe que o nosso povo não tem formação política como em outros países, outras nações. Hoje, há interferência grande da política partidária no movimento em si, porque as lideranças, muitas delas, não têm uma ideia própria e obedece àquele partido político ou cidadão que dá ajuda financeira. São poucas lideranças que têm coragem de dizer o que pensam e sentem, então têm atrapalhado em parte [a existência do debate qualificado] (A).

Gohn (2004) destaca a importância de que conselheiros tenham formação e consciência crítica, para que compreendam os processos em que se 
inserem e, mais especificamente, os critérios que deveriam subsidiar suas decisões para o atendimento das necessidades da população.

A realização de cursos de capacitação para os membros dos CRUs propiciados pela gestão pública foi ressaltada, destacando-se o papel indutivo do Estado no fortalecimento do processo de democracia participativa, na perspectiva de se ampliar o acesso às informações (Jacobi, 2004).

Houve interesse, por intermédio do prefeito, de aprimorar esse trabalho e procurar dar conhecimento para os conselheiros regionais, então ele promoveu um curso na universidade para todos os conselheiros regionais se comporem melhor no entendimento da administração pública, como trabalhar no bairro, como trazer as reivindicações (B).

Participei do Plano Diretor em 1988, (...) aí veio a capacitação dos conselheiros (...) o prefeito (...) dava a capacitação, para que nós conselheiros defendêssemos o bairro, o nosso conjunto, como conselheira (B).

A atuação do Estado nos locais da iniciativa também foi ressaltada como propulsora da presença da população nos fóruns institucionalizados de participação.

Eles criavam mutirões e iam para os bairros onde tinha maior foco de favelas, essas necessidades da população que eles tentavam lá estimular para que as pessoas participassem desse trabalho para melhorar a qualidade de vida do bairro, e foi através desse projeto que os conselhos começaram a ser mais ativos, antes os conselhos não eram muito ativos (L).

De forma geral, quanto ao processo de participação nas instâncias colegiadas, embora houvesse fragilidades no aspecto da informação, os dados apontaram percepção quanto ao fortalecimento das lideranças nos bairros, expressas num movimento organizado de articulação, com a união de lideranças em torno de objetivos comuns. Embora não se tenham apresentado elementos para análise da dinâmica, o movimento destacado remeteu ao significado para os conselheiros quanto à forma como participavam, seus sentimentos e posicionamentos ideológicos quanto à participação. Os discursos sugeriram a formação de uma espiral de participação, um movimento crescente, estimulado por uma rede de apoio comunitário:

Foi quando conheci o N., então um apadrinhou o outro, e sempre com os conhecimentos que vinham pra gente, as coisas vinham tão depressa que a gente não conseguia abraçar tudo, tinha que buscar mais pessoas, então um levava um, um levava outro, então foi crescendo esse leque. Esse conhecimento da gente hoje nos 
bairros é muito grande (...) a perspectiva é de crescimento. (...) o modelo que eu tenho de ligação comunitária social foi através da União Campo-Grandense de Associação de Moradores em Favelas [Ucaf] (L).

(...) processo muito bonito (...) existia a figura da coligação, que era uma coisa interessante, por exemplo, tinha quatro comunidades num bairro, três, e só tinha uma vaga para um, fazia uma coligação e aquela uma representava todas (...) é interessante isso (A).

A questão da consciência política e pública emergiu como fundamental no exercício dessa democracia participativa.

A parte do conselho é muitíssimo importante, a experiência foi maravilhosa, foi sofredora, a gente fez parte do início, começou a participar discutindo o orçamento da prefeitura, e muita reivindicação que a gente estabelecia como prioridade não era feita, não era passada, mas a gente ia no outro ano, no outro orçamento, brigava de novo por aquilo, porque a gente tinha as nossas justificativas de que aquilo era realmente o mais importante (B).

(...) a liderança, quem é líder comunitário, eu sou um líder comunitário, eu já tenho que pensar na coletividade (B).

Houve discursos que destacaram a participação como trabalho voluntário, de cunho ideológico, que perpassava a dimensão individual em prol do bem coletivo:

Nós, como lideranças, trabalhamos como voluntários, trabalhamos pelo povo para ajudar aquele que precisa, e trabalhamos com amor e carinho para ajudar, sem interesse próprio (A).

A nossa região tinha muita necessidade, talvez por isso, e a gente aceitou para levar alguma coisa boa para o nosso bairro (S).

O objetivo principal era em prol da comunidade, e enxergando isso aí, eu fui convidado e eu ia aos debates, para discutir (S).

A questão da representação no interior das experiências de participação foi estudada por Lüchmann (2007), que analisou a dimensão da participação e a representação coletiva que ocorre por intermédio das organizações da sociedade civil. A autora reafirma as palavras de Young, em Inclusion and democracy (2006), quanto à responsabilidade de representantes e cidadãos num processo de representação legítima: “estes precisam estar dispostos e aptos 
a mobilizar uns aos outros para participar ativamente tanto do processo de autorização quanto do de prestação de contas" (Lüchmann, 2007, p. 165). Há a necessidade de se promover conexão entre representantes e representados, e o lócus dos conselhos pode ser espaço público conector.

Na percepção dos conselheiros, as principais barreiras ou dificuldades para a participação social foram falta de presença da população nas instâncias participativas, falta de conhecimento e fragilidade do acesso à informação, dificuldades no exercício de atuação como conselheiro e descrença no processo participativo, causando a evasão de lideranças:

A comunidade cobra muito, mas pouco participa, pouquíssimo, até em eleição. Se o seu bairro tem dois, três mil moradores, você faz uma eleição não vai quatrocentos votar, só que aqueles outros vêm cobrar e não participam. Dificilmente, cinquenta por cento da comunidade participa (P).

A gente sente falta de diálogo, falta de informação. Esse repasse que às vezes chega e fica preso não é repassado para a frente, e as pessoas, os responsáveis, os representantes que estão em contato com a comunidade, elas precisam dessas informações para divulgar nosso trabalho dentro da região (B).

Alguns bairros, às vezes, recebem algo que foi indicado pelo conselho, outros bairros vão receber daqui a três anos (...) então, isso desmotiva muito os conselheiros (...) o pessoal espera um ano, dois anos, três anos, e aí, mas o que esse conselho está servindo para vocês? (L).

O interessante é que nós, conselheiros, quando chegamos ao bairro com informações que tal coisa foi encaminhada, acham que vai acontecer de imediato, e isso vem de quem participa, da gente, o que pode acontecer e é o que está acontecendo, que quando começa a levar muito tempo da coisa acontecer vai acumulando pessoas... E um 'diz que me diz' e a gente fica mal com a comunidade (L).

Entre as fragilidades, destacou-se a descrença no processo participativo. Ao se considerar a configuração política implementada no âmbito do município como nova, entende-se que este deva ser um desafio a se enfrentar na tarefa de se consolidar a democracia.

Outro aspecto é a articulação das instâncias participativas com os legislativos locais, que, segundo Avritzer (2006, p. 42), "têm sido, via de regra, postos em um segundo plano na sua capacidade decisória", pois há dificuldades nas articulações entre os arranjos participativos e os representantes dos legislativos. Com baixo poder de decisão, essas instâncias perdem legitimidade na política local. Nessa perspectiva, o autor recomenda mudanças normativas, uma vez que “a legislação existente entende os conselhos de 
políticas como parte da estrutura do Executivo, o que, a nosso ver, parece ser um equívoco" (Avritzer, 2006, p. 42). Ele sugere avanços na melhoria das articulações entre legislativos locais e arranjos participativos locais.

A dificuldade de articulação com o legislativo foi relatada pelos representantes de governo, os próprios técnicos, no processo de institucionalização dos CRUs:

A melhor coisa que aconteceu na minha vida foi poder trabalhar nessa proposta, se discutia e se formavam grupos de mulheres que trabalhavam questões éticas dentro do clube de mães, questões éticas e morais e administrativas dentro da associação de moradores, só que começou a incomodar. Começou a incomodar quem? O poder público, como que você tem técnicos da prefeitura induzindo mudanças? Começou a incomodar vereadores, mas a gente conseguiu segurar, a gente recuava, ia mais para a frente e dava uma recuadinha, mas trabalhava, não do jeito que gostaríamos porque a estrutura era muito pequena, um assistente social, um psicólogo e três auxiliares para atender toda a região (T).

E também por representantes da população:

Muitos bairros foram asfaltados através de propostas de conselheiros, mesmo que os vereadores vão dizer que é deles, não tem problema, mas algumas conquistas foram conseguidas pela comunidade, asfalto. A gente pode lembrar de algumas regiões, tem uma região do Grande Los Angeles, Centro-Oeste, Lageado (A).

Em outros momentos, durante a realização dos grupos focais, houve indicação de distanciamento entre o setor legislativo e a comunidade. O distanciamento do poder legislativo pode comprometer a prática democrática (Pinto, 2004), como se pôde observar no discurso a seguir:

Para que o parque do Ayrton Senna seja transformado num centro olímpico, para ter mais atividade para os jovens, para os idosos, então isso é nossa luta, porque muitos vão lá, se elegem de quatro em quatro anos e nunca mais aparecem, e não é isso que nós queremos, porque se todos os candidatos soubessem trabalhar, cada mês visitassem as entidades, soubessem do que eles precisam, sempre eles iam ter muito voto, mas não faz isso, né (A)?

Silva (2007, p. 143), ao estudar o processo participativo, apontou a atuação dos CRUs como "significativa no processo permanente de planejamento do município", na medida em que se configurava um "mecanismo de ampliação do debate e melhor aplicação dos recursos municipais". Mas também indicou fragilidades: falta de visão dos conselheiros quanto à região urbana como um todo e mobilização não equânime dos moradores. Havia regiões com maior 
número de conselheiros que outras, e essas regiões apresentavam carência de serviços públicos e equipamentos, o que podia explicar o fato de os moradores se sentirem mobilizados para reivindicar medidas do poder público.

Com a finalização oficial da iniciativa em 2004, outro projeto da Prefeitura de Campo Grande, em 2005, surgiu com o objetivo de valorizar a atuação dos conselheiros regionais, efetivar a gestão democrática na administração municipal e fomentar iniciativas para a efetivação dos Objetivos do Desenvolvimento do Milênio: o denominado Programa Comunidade Viva (Campo Grande, 2006c). Na realização dos grupos focais, as falas mostraram a 'sensação de continuidade' do PVSB com o Programa Comunidade Viva.

Um dos técnicos do PVSB afirmou que a sustentabilidade foi identificada como continuidade das ações e dos programas desenvolvidos. Declarou que uma estratégia utilizada foi reunir conselheiros e discutir a sustentabilidade após o término dos recursos destinados às obras:

O recurso acabou para as obras de construção, mas nós tínhamos uma forma de tentar viabilizar a sustentabilidade de cada região, então foram reunidos os conselheiros, fazendo reuniões para passar que eles poderiam continuar o trabalho, dar continuidade $(\mathrm{T})$.

No depoimento de um dos representantes de governo, a questão da sustentabilidade estava diretamente ligada ao processo de fortalecimento da comunidade. Ao entender que o poder público fez a parte dele com o cumprimento das metas estabelecidas, o depoimento transferiu a responsabilidade pela continuidade das ações para a comunidade; ou seja, entendeu que o PVSB teve início, meio e fim e que novas ações dependeriam da mobilização da comunidade:

(...) essa sustentabilidade está ligada diretamente ao fortalecimento daquela comunidade do que não é continuidade enquanto projeto, porque esse projeto tinha uma finalidade: um começo, meio e fim - que era o que melhorar os indicadores daquela população, então a gente pergunta assim, quais foram os nossos indicadores do início, quais são os números ao final, ao meio do projeto, ao final do projeto. Houve melhoria realmente, então houve ganho, então o projeto tem ações continuadas em grande parte: a escolarização de adultos, hoje, ainda continua (T).

Também se apontou a própria comunidade como responsável pela manutenção dos equipamentos:

A questão dessa sustentabilidade era fundamental no seguinte aspecto: aquelas lideranças tinham que estar conscientes da importância que tinham para aquela localidade, não adiantava nada se nós fizéssemos o campo de futebol lá e eles não 
assumissem a responsabilidade social daquele equipamento. (...) dos campos de futebol são eles que fazem a manutenção, eles cuidam do espaço, aquela associação fica responsável por aquela localidade, período de seca eles não deixam jogar, eles que cuidam e operam aquela localidade (T).

Esses depoimentos remeteram à importância de algumas dimensões estudadas por Mendes, Plaza e Walllerstein (2014) quanto aos aspectos facilitadores e dificultadores para a sustentabilidade de iniciativas de promoção da saúde. Os discursos de alguns representantes da população sinalizaram o entendimento da sustentabilidade como 'continuidade' do PVSB em outros projetos decorrentes dele ou como se a permanência das obras e sua utilização significassem a continuidade do projeto.

(...) por exemplo, da saúde, a continuidade é dada no posto de saúde ou no PSF [Programa Saúde da Família] (...) dá-se a continuidade daquele trabalho realizado naquela escola, a SAS [Secretaria de Assistência Social] da mesma forma, dá uma continuidade ao trabalho (I).

(...) dá continuidade em outros projetos, e assim outros projetos vieram surgindo, Comunidade Viva, os projetos que tem nas escolas, são várias outras situações que foram criadas a partir do 'Viva Seu Bairro', pelo menos é o que eu vejo (I).

É possível estabelecer uma conexão entre a ideia de sustentabilidade e a criação de novas institucionalidades, com a possibilidade do refazer, do criar contínuo. Nesse sentido, para Mendes, Plaza e Walllerstein (2014), o significado de sustentabilidade se apoia em buscar soluções amplas e duradouras de iniciativas de promoção da saúde, cuja continuidade do programa deve estar ancorada por um complexo sistema de relações, permeadas de atores e instituições, para criar 'novas institucionalidades', ou arranjos institucionais 'inovadores', que possibilitem romper com o modelo centrado em instituições ou agências isoladas.

Entretanto, outro conselheiro apontou a não continuidade do PVSB em razão da mudança de gestão, que causou rupturas no processo administrativo:

(...) deixa saudade, você perguntou por que acabou, os programas, eles são criados para aquela equipe que está na frente da administração, seja presidente de bairro, seja de conselho, ou até mesmo poder público pra poder chegar. Então troca de comando é muito difícil um administrador ou um presidente do bairro assumir aquela casa e querer dar continuidade igualzinha (I).

Fernandez e Mendes (2007) já apontavam para a descontinuidade de programas durante a transição da gestão administrativa, ressaltando que 
deveria ser pauta permanente a reflexão de gestores sobre a sustentabilidade dos projetos, ações e políticas.

Os depoimentos foram contraditórios quanto à percepção da sustentabilidade do PVSB. Alguns relacionavam o conceito com a continuidade do próprio programa, outros com a criação de novas institucionalidades, programas e projetos advindos da gestão municipal, como é o caso do Comunidade Viva.

Não emergiu dos discursos dos grupos focais qualquer debate, discussão ou movimento que tivesse sido utilizado para a reflexão da sustentabilidade. Percebeu-se como incipiente a incorporação de uma prática avaliativa na gestão e, em especial, a clareza do conceito de sustentabilidade no planejamento da iniciativa e dos indicadores operacionais que poderiam ter sido utilizados no monitoramento.

Nem representantes de governo nem conselheiros indicaram a importância do Colegiado de Gestão ou da UTC como espaço de discussão e proposição de ações ou de novos arranjos que pudessem fomentar outros projetos. Kleba, Comerlatto e Frozza (2015) discutem a importância da utilização dos instrumentos e mecanismos de gestão para ampliar a participação na gestão pública municipal. Em investigação sobre os instrumentos utilizados nos processos decisórios pelos Conselhos Municipais de Assistência Social e de Saúde em Chapecó (SC), identificaram-se as comissões internas, capacitação, conferências e comunicação com outras organizações. A utilização de mecanismos pode ampliar o processo participativo desde que sejam espaços legitimados por aqueles que os compõem.

Nessa iniciativa, técnicos e gestores sinalizaram as diferenças entre os bairros quanto à participação, alguns mais participativos e envolvidos, o que se relaciona à singularidade de cada local, à forma como a dinâmica social se apresenta. No entanto, as maiores barreiras encontradas, segundo o gestor, diziam respeito à descrença inicial da população no poder público municipal:

As barreiras foram: a descrença, a descrença no poder público. Poucos acreditavam que se investisse tamanho volume de recursos financeiros em bairros pouco densamente populosos e que era a pobrezada, a bandidagem, o alcoolismo que ingressava lá, e nós fizemos justamente isso com o intuito de vencermos as barreiras psicológicas, aumentarmos a autoestima da população, fazermos com que eles se sentissem vistos, olhados, cuidados pelo poder público (G).

Os resultados do estudo corroboram as conclusões de Westphal e colaboradores (2013), que também demonstraram que valores como participação, construção coletiva de políticas e sustentabilidade (seja como continuidade, seja como novas institucionalidades) passaram a integrar o ideário e a experiência dos sujeitos diretamente envolvidos, além de interferir para que ações 
propulsoras fossem adotadas e implementadas para promover a saúde e a qualidade de vida dos cidadãos que vivem nesses locais.

Por certo, desafios encontram-se presentes nas instâncias de democracia participativa, como nos CRUs, em que se questiona a representatividade dos participantes em nome de suas regiões, seja pela pouca participação ou envolvimento, seja pela conformação de dada administração local. No entanto, os desafios podem ser enfrentados com contínuo estímulo ao processo de participação de atores diversificados, com mecanismos e instrumentos que propiciem envolvimento, conhecimento e informação. Nessa iniciativa, embora se reconheçam as fragilidades, os resultados apontaram avanços significativos na dinâmica da participação no município, a partir da institucionalização do conselho temático voltado ao desenvolvimento urbano.

\section{Considerações finais}

O estudo aqui apresentado procurou mostrar que as instâncias participativas criadas se institucionalizaram para o desenvolvimento técnico-operacional das ações do PVSB, mas não serviram como espaços para discussão e proposição de novas ações ou outros arranjos institucionais. Embora o município de Campo Grande já tivesse experiência anterior de implantação de colegiados regionais, organizados como canais de participação representativa, havia indícios de que a iniciativa desencadeou maior envolvimento dos conselheiros regionais urbanos nas decisões do planejamento urbano e também uma experiência diferenciada, na prática, dos representantes de governo, o que significou avanços nos processos democráticos - possivelmente pelo arranjo inovador de gestão, característico das iniciativas de promoção da saúde. No entanto, a questão da necessidade de formação política de conselheiros emergiu como necessária para a qualificação da participação. A dificuldade no acesso à informação e a descrença no processo participativo também apareceram como causas da evasão de lideranças.

Puderam ser percebidos o fortalecimento dos espaços colegiados e a união das lideranças nos bairros em torno de objetivos comuns. Concluiu-se que, apesar das dificuldades e limitações, houve a formação de uma espiral crescente de participação, estimulada por uma rede de apoio comunitário.

A forma de se trabalhar integradamente, com arranjo institucional inovador, articulado intra e intersetores da administração, envolvendo múltiplos participantes, expressou-se em riqueza para a dinâmica municipal, pois houve a percepção quanto às parcerias e alianças que a iniciativa promoveu. Os representantes do governo buscaram desenvolver ações de forma integrada e mecanismos que buscassem a ação intersetorial. No entanto, o distanciamento do poder legislativo comprometeu a prática democrática no estabe- 
lecimento de canais de comunicação ágeis e no apoio à continuidade de programas considerados satisfatórios para que se consolidassem mesmo após a mudança da gestão.

Sugere-se que as decisões da gestão devem apoiar-se em aspectos técnicos e operacionais e ousar novos arranjos institucionais, mediante canais de participação efetivamente representativos que possam ser propulsores do avanço de políticas públicas comprometidas com a qualidade de vida da população.

\section{Colaboradoras}

Crhistinne Cavalheiro Maymone Gonçalves e Cláudia Maria Bógus trabalharam na concepção, delineamento, análise e interpretação dos dados, redação final do artigo, revisão crítica e aprovação da versão a ser publicada.

Resumen La investigación presentada en este artículo buscó conocer la participación social en una iniciativa de la promoción de la salud desarrollada en Campo Grande, Mato Grosso do Sul, Brasil. Se trató de una investigación realizada en 2009 con enfoque cualitativo, en que se realizaron análisis documental, entrevistas (con gestores y técnicos) y grupos focales (con consejeros regionales), y análisis de contenido con triangulación de los datos. La percepción en cuanto a la participación social no se restringió a la experiencia, pues se destacaron la institucionalización de canales de participación en el municipio y los consejos regionales urbanos, considerados como avance en los procesos democráticos, propulsores de mayor participación de los consejeros en las decisiones de la planificación urbana. No obstante, se destacaron barreras al ejercicio democrático: necesidad de formación política de consejeros, fragilidad de presencia de la población en las instancias participativas, dificultad de articulación con el poder legislativo, falta de conocimiento y acceso a la información, dificultades en la actuación como consejero y descrédito en el proceso participativo, causando evasión de líderes. Se observaron el fortalecimiento de estos espacios colegiados y la unión de los líderes en los barrios en torno a objetivos comunes, con la formación de una espiral creciente de participación, estimulada por una red de apoyo comunitario.

Palabras clave participación social; políticas públicas; promoción de la salud. 


\title{
Notas
}

\author{
1 Universidade Federal da Grande Dourados, Mato Grosso do Sul, Brasil. \\ $<$ crhismay@gmail.com> \\ Correspondência: Rua Quintino Bocaiuva, 817, apto. 02, Centro, CEP 79080-030, \\ Dourados, Mato Grosso do Sul, Brasil. \\ 2 Universidade de São Paulo, Faculdade de Saúde Pública, São Paulo, Brasil. \\ $<$ claudiab@usp.br> \\ ${ }^{3}$ Não houve financiamento para a pesquisa. Não há conflitos de interesse de qualquer \\ natureza, seja pessoal, comercial, acadêmico ou financeiro.
}

\section{Referências}

AVRITZER, Leonardo. Reforma política e participação no Brasil. In: AVRITZER, Leonardo; ANASTASIA, Fátima (orgs.). Reforma política no Brasil. Belo Horizonte: Ed. UFMG, 2006. p. 35-43. Disponível em: <www.ligiatavares. com/gerencia/uploads/arquivos/d2af15de8 666c5382e11d8660f15dd31.pdf>. Acesso em: 18 dez. 2016.

BÓGUS, Cláudia M. Conselhos gestores de políticas públicas no município de São Paulo: identidade, limitações e potencialidades na perspectiva da promoção da saúde. $220 \mathrm{f}$. Tese (Livre-Docência em Saúde Pública) Faculdade de Saúde Pública, Universidade de São Paulo, São Paulo, 2009.

BÓGUS, Cláudia M.; WESTPHAL, Márcia F. Participação social e cidadania em movimentos por cidades saudáveis. In: FERNANDEZ, Juan C. A.; MENDES, Rosilda (orgs.). Promoção da saúde e gestão local. São Paulo: Hucitec, 2007. p. 61-83.

BRASIL, Flávia P. D. et al. Participação, desenho institucional e alcances democráticos: uma análise do Conselho das Cidades (ConCidades). Revista de Sociologia e Politica [on line], Curitiba, v. 21, n. 48, p. 5-18, 2013.
Disponível em: <http://dx.doi.org/10.1590/ S0104-44782013000400001>. Acesso em: $1^{\circ}$ mar. 2016.

CAMPO GRANDE (Prefeitura). Programa de apoio a projetos multissetoriais: projeto multissetorial integrado Viva Seu Bairro. Campo Grande: Planurb-PMCG, 2001.

CAMPO GRANDE (Prefeitura). Perfil socioeconômico de Campo Grande, 2005. Campo Grande: Planurb-PMCG, 2005.

CAMPO GRANDE (Prefeitura). Edital n. 1, de 25 de janeiro de 2006 - Sistema municipal de planejamento: atualização e cadastramento de entidades. Diário Oficial [de] Campo Grande, Campo Grande, MS, n. 1985, 26 jan. 2006a. Parte I, p. 2. Disponível em: <http://portal. capital.ms.gov.br/diogrande $>$. Acesso em: 19 dez. 2016.

CAMPO GRANDE (Prefeitura). Edital n. 2, de 22 de fevereiro de 2006 - Regulamento para eleição de conselheiros regionais. Diário Oficial [de] Campo Grande, Campo Grande, MS, n. 2009, 3 mar. 2006b. Parte I, p. 5-7. Disponível em: <http://portal.capital.ms.gov. br/diogrande>. Acesso em: 19 dez. 2016. 
CAMPO GRANDE (Prefeitura). Comunidade Viva Notícias, Campo Grande, ano 1, n. 2, p. 1-8, 2006c.

CAMPO GRANDE (Prefeitura). Aspectos físicos e territoriais. Perfil socioeconômico de Campo Grande, 2007-2008. Campo Grande: Planurb-PMCG, 2007. p. 46-57.

CAMPO GRANDE (Prefeitura). Planurb - Instituto Municipal de Planejamento Urbano (PMCG). Atividades 2008. Campo Grande: Planurb-PMCG, 2008.

FERNANDEZ, Juan C. A.; MENDES, Rosilda. Gestão local e políticas públicas para a qualidade de vida. In: FERNANDEZ, Juan C. A.; MENDES, Rosilda (orgs.). Promoção da saúde e gestão local. São Paulo: Hucitec, 2007. p. 41-60.

GOHN, Maria G. Conselhos gestores e participação sociopolitica. 2. ed. São Paulo: Cortez, 2003.

GOHN, Maria G. Empoderamento e participação da comunidade em políticas sociais. Saúde e Sociedade, São Paulo, v. 13, n. 2, p. 20-31, 2004. Disponível em: <www.scielo. $\mathrm{br} / \mathrm{pdf} / \mathrm{sausoc} / \mathrm{v} 13 \mathrm{n} 2 / 03 . \mathrm{pdf}>$. Acesso em: 22 set. 2009.

GUIZARDI, Francini L.; PINHEIRO, Roseni. Dilemas culturais, sociais e políticos da participação dos movimentos sociais nos conselhos de saúde. Ciência \& Saúde Coletiva, Rio de Janeiro, v. 11, n. 3, p. 797-805, 2006.

JACOBI, Pedro. A gestão participativa de bacias hidrográficas no Brasil e os desafios do fortalecimento de espaços públicos colegiados. In: COELHO, Vera S. R. P.; NOBRE, Marcos (orgs.). Participação e deliberação. São Paulo: Editora 34, 2004. p. 270-289.

KLEBA, Maria E.; COMERLATTO, Dunia; FROZZA, Kenia M. Instrumentos e mecanismos de gestão: contribuições ao processo decisório em conselhos de políticas públicas. Revista de Administração Pública [on line], Rio de Janeiro, v. 49, n. 4, p. 1.059-1.079, 2015. Disponível em: <http://dx.doi.org/
10.1590/0034-7612125666>. Acesso em: $1^{\circ}$ mar. 2016.

LABRA, Maria E. Conselhos de saúde: dilemas, avanços e desafios. In: LIMA, Nísia T. et al. (org.). Saúde e democracia: história e perspectivas do SUS. Rio de Janeiro: Editora Fiocruz, 2005. p. 353-383.

LÜCHMANN, Lígia H. H. A representação no interior das experiências de participação. Lua Nova, São Paulo, v. 70, p. 139-170, 2007. Disponível em: <www.scielo.br/pdf/ln/n70/ a07n70.pdf>. Acesso em: 20 fev. 2009.

MENDES, Rosilda; PLAZA, Veronica; WALLERSTEIN, Nina. Sustainability and power in health promotion: community-based participatory research in a reproductive health policy case study in New Mexico. Global Health Promotion, Thousand Oaks, v. 23, p. 61-74, 2014.

MILANI, Carlos R. S. O princípio da participação social na gestão de políticas públicas locais: uma análise de experiências latino-americanas e europeias. Revista de Administração Pública, Rio de Janeiro, v. 42, n. 3, p. 551-579, 2008. Disponível em: <www. scielo.br/pdf/rap/v42n3/a06v42n3.pdf $>$. Acesso em: 22 set. 2009.

MINAYO, Maria C. S. Introdução. In: MINAYO, Maria C. S.; ASSIS, Simone G.; SOUZA, Edinilsa R. (orgs.). Avaliação por triangulação de métodos: abordagem de programas sociais. Rio de Janeiro: Editora Fiocruz, 2005. p. 15-51.

PINTO, Cecília R. J. Espaços deliberativos e a questão da representação. Revista Brasileira de Ciências Sociais, São Paulo, v. 19, n. 54, p. 97-113, 2004. Disponível em: <www.scielo. br/pdf/rbcsoc/v19n54/a06v 1954.pdf $>$. Acesso em: 22 set. 2009.

SALES, Teresa. Raízes da desigualdade social na cultura política brasileira. Revista Brasileira de Ciências Sociais, São Paulo, n. 25, 1994. Disponível em: <www.anpocs.org.br/ portal/publicacoes/rbcs_00_25/rbcs25_02>. Acesso em: $18 \mathrm{dez} .2016$. 
SILVA, Welington F. M. A descentralização na política urbana de Campo Grande como possibilidade de desenvolvimento. $151 \mathrm{f}$. Dissertação (Mestrado em Geografia) - Universidade Federal de Mato Grosso do Sul, Aquidauana, 2007

SOUZA, Celina. Governos locais e gestão de políticas sociais universais. São Paulo em Perspectiva, São Paulo, v. 18, n. 2, p. 27-41, 2004. Disponível em: <www.scielo.br/pdf/ spp/v18n2/a04v18n2.pdf>. Acesso em: 22 set. 2009.

TATAGIBA, Luciana. Os conselhos gestores e a democratização das políticas públicas no Brasil. In: DAGNINO, Evelina (org.). Sociedade civil e espaços públicos no Brasil. São Paulo: Paz e Terra, 2002. p. 47-103.
WESTPHAL, Marcia F. et al. Práticas democráticas participativas na construção de agendas sociais de desenvolvimento em municípios do Sudeste brasileiro. Ambiente \& Sociedade [on line], São Paulo, v. 16, n. 2, p. 103-128, 2013. Disponível em: <http://dx.doi.org/ 10.1590/S1414-753X2013000200007>. Acesso em: $1^{\circ}$ mar. 2016.

YOUNG, Iris M. Representação política, identidade e minorias. Tradução de Alexandre Morales. Lua Nova, São Paulo, n. 67, p. 139-190, 2006. Traduzido de 'Inclusion in democracy', cap. 4.

Recebido em 01/02/2015

Aprovado em 23/09/2016 